\title{
A PÁGINA OMISSA: CONTRIBUIÇÕES PARA UMA HISTÓRIA DO ENSINO DE LÍNGUAS NO BRASIL
}

\author{
José Carlos Paes ALMEIDA FILHO*
}

- RESUMO: A aprendizagem e o ensino de línguas formam uma área prática profissional e uma área teórica. Essa área se conhece por Aquisição e Ensino de Línguas (AELin) ou, simplesmente, Ensino de Línguas, e inclui o processo formador de agentes que concorrem a esses processos. Esses processos existiram desde sempre na história educacional do país, mas tardamos em reconhecer e ter reconhecida essa narrativa do seu vir-a-ser como especialidade tributária. A bibliografia é escassa e há muito pouca oferta dessa especialidade como disciplina nos currículos ditos de Letras na grande área da Linguagem. Neste artigo, retomo a escrita sobre a trajetória de personagens, fatos e enredo da história do ensino de línguas no Brasil não para sinalizar períodos e pontos de emergência de consciência de área, mas, para discutir, principalmente, a falta de estudos de natureza histórica para o ensino de línguas (estrangeiras e o Português na perspectiva de LE) e para a constituição de uma disciplina científica madura e pujante de história nos currículos de graduação em Letras e de pós nos estudos de ensino e aprendizagem de línguas no país.

- PALAVRAS-CHAVE: História do ensino de línguas no Brasil. Aprendizagem e ensino de línguas. Ensino de línguas: aspectos históricos. História do ensino de línguas. Formação de professores de línguas.

\section{Introdução}

Considero que o Ensino de Línguas (materna e outras), com profissionais nela atuando em carreiras diversas na educação regular e complementar, constitui uma área de atuação profissional e teórica ao mesmo tempo. Essa área dita aplicada está vinculada, por sua vez, à área maior de estudos aplicados denominada Linguística Aplicada. A área de Ensino de Línguas ou Aprendizagem e Ensino de Línguas (AELin) inclui também a formação adequada dos agentes dos processos de aquisição e ensino, ou seja, aprendentes, professores e, eventualmente, terceiros importantes.

Essa área profissional consolidou ao longo de pelo menos 50 séculos uma praxis de trabalho e a necessidade de desenvolver através da pesquisa um corpo de

\footnotetext{
* UnB - Universidade de Brasília. Instituto de Letras - Departamento de Línguas Estrangeiras e Tradução. Brasília - DF - Brasil. 70910-900 - jcpaesalmeidafilho@gmail.com
} 
conhecimentos próprio reconhecível que serve de balizador para confrontar teoria informal composta de intuiçóes, memórias e crenças sobre os processos envolvidos. A natureza do conhecimento e dos procedimentos justificáveis associados aos processos inter-relacionados de aprender e ensinar línguas, por lidar com fenômenos da superfície da vida social envolvendo o uso de línguas, é invariavelmente assumida como disciplina aplicada pelos praticantes da área. A pesquisa que pratica é invariavelmente do tipo aplicado, isto é, focaliza questóes práticas de superfície colocadas nas profissôes e práticas de linguagem no grau de complexidade em que são construídas para investigaçáo sistemática.

Conhecimentos teóricos de natureza aplicada como os da área de AELin, somados a outros das áreas de Tradução, Lexicografia Aplicada, Secretariado Executivo, Patologias da Linguagem e Relaçóes Sociais Mediadas pela Linguagem, entre outros, fazem parte da área teórica mais ampla da Linguística Aplicada. Juntamente com as duas irmãs teóricas disciplinares, a Linguística e a Literatura (envolvendo os estudos literários e a teoria literária, entre outros), a Linguística Aplicada compóe a Grande Área da Linguagem. A rigor, a LA não é uma disciplina, mas uma constelação de disciplinas do tipo aplicado, mas a sua relação com as irmãs se mantém. Potencialmente, a área de AELin poderia também intersectar formalmente a Pedagogia Geral se houvesse tradição generalizada para essa prática teórica. Intersecçôes teóricas esporádicas e específicas com a Educação são, contudo, praticadas interdisciplinarmente no país e no mundo.

Neste artigo, vamos interpelar a área de AELin e perguntar se há aspectos da sua construção teórica que não têm merecido tratamento adequado para além do confronto entre a agenda de pesquisa formal explícita e a base teórica informal constituída pelas crenças e arredores. Analisaremos se há, de fato, uma lacuna ou página omissa no livro do Ensino de Línguas que deixa de retratar aspectos do desenvolvimento histórico dessa área no país que deixa marcas na construção prática da profissão.

\section{Acervo da história do ensino de línguas}

Uma coisa é existir uma área e outra coisa é haver consciência dessa área. A história do Ensino de Línguas no mundo e no Brasil incrementam de modo decidido o desenvolvimento dessa consciência de área ou disciplina. No plano mundial, há alguns grandes livros de natureza histórica para a área de AELin:

- TITONE, R. A. Teaching foreign languages: an historical sketch. Washington: Georgetown University Press, 1968.

- KELLY, L. G. 25 centuries of language teaching. Rowley: Newbury House, 1969.

- HOWATT, A. P. R. A history of English language teaching. Oxford: Oxford University Press, 1984. 
- GERMAIN, J. C. Evolution de l'enseignement des langues: 5 mil ans d'histoire. Paris: CLÉ International, 1993.

Esses grandes livros publicados na segunda metade do século vinte contam a saga metodológica e de políticas com reformas de nossos antepassados profissionais do Ensino de Línguas. Essa produção mostra máximo vigor no período de maior vitalidade científica já visto ao longo dos cinco mil anos de história registrada: o século 20.

No Brasil temos uma estante apreciável de livros, artigos e relatos de pesquisa que não nos envergonha se comparada à melhor produção registrada em outros países do globo. Vejamos o que há:

\section{Livros brasileiros}

- CHAGAS, V. Didática especial das línguas modernas. São Paulo: Nacional, 1957.

- CELANI, M. A. A. (Org.). Redescobrindo as origens: ensino de língua estrangeira. São Paulo: EDUC, 1997.

- SILVEIRA, M. I. M. Línguas estrangeiras: uma visão histórica das abordagens, métodos e técnicas de ensino. Maceió: Catavento, 1999.

- STEVENS, C. T.; CUNHA, M. J. C. Caminhos e colheitas: ensino e pesquisa na área de inglês no Brasil. Brasília: Ed. da UnB, 2003.

- CASIMIRO, G. S. A língua inglesa no Brasil: contribuiçóes para a história das disciplinas escolares. Campo Grande: Uniderp, 2005.

- VIDOTTI, J. J. V. Política de língua estrangeira: o século XIX no Brasil. Saarbrücken: Novas Ediçôes Acadêmicas, 2014.

\section{Artigos e capítulos de livros}

LEFFA, V. O ensino das línguas estrangeiras no contexto nacional. Revista Contexturas, São Paulo, n. 4, p. 13-24, 1999.

ALMEIDA FILHO, J. C. P. de. Ontem e hoje no ensino de línguas no Brasil. In STEVENS, C. T.; CUNHA, M. J. C. (Org.). Caminhos e colheitas: ensino e pesquisa na área de inglês no Brasil. Brasília: Ed. da UnB, 2003. p.19-34.

ALMEIDA FILHO, J. C. P. O português como língua não-materna: concepções e contextos de ensino. Museu da Língua Portuguesa Estaçáo da Luz, São Paulo, 14 
maio 2009. Disponível em: <http://www.museudalinguaportuguesa.org.br/colunas_ interna.php?id_coluna=4>. Acesso em: 05 abr. 2015.

Artigo para a base de consultas sobre estudos da língua no Museu da Língua Portuguesa, em São Paulo.

ALMEIDA FILHO, J. C. P. de. Ensino de Português língua estrangeira/EPLE: a emergência de uma área. In: ALMEIDA FILHO, J. C. P. (Org.). Fundamentos de abordagem e formaçáo no ensino de PLE e de outras línguas. Campinas: Pontes, 2011. p.93-104.

\section{Teses e Dissertações}

PEDREIRO, S. O movimento comunicativo de ensino de línguas estrangeiras no Brasil. 2002. 101f. Dissertação (Mestrado em Linguística Aplicada) - Universidade de Brasília, Brasília, 2002.

OLIVEIRA, L. E. M. de. A historiografia brasileira da literatura inglesa: uma história do ensino do inglês no Brasil (1809-1951). 1999.194f. Dissertação (Mestrado em Lingüística Aplicada) - Universidade Estadual de Campinas, Instituto de Estudos da Linguagem, Campinas, 1999. Disponível em: <http://www.unicamp.br/iel/ memoria/projetos/teses/tese19.doc>. Acesso em: 25 set. 2009.

. A instituição do ensino das línguas vivas no Brasil: o caso da língua Inglesa (1809-1890). 2006. 373f. Tese (Doutorado em Educação) - Pontifícia Universidade Católica, São Paulo, 2006.

VIDOTTI, J. J. V. Políticas linguísticas para o ensino de língua estrangeira no Brasil do século XIX, com ênfase na língua inglesa. 2012. 247f. Tese (Doutorado em Estudos Linguísticos e Literários em Inglês) - Universidade de São Paulo, São Paulo, 2012.

BATISTA, M. C. Pontos e entrepontos: apontamentos cronológicos para uma narrativa histórica do ensino de língua portuguesa: L1 em ambiente escolar no Brasil. 2014. 254f. Dissertação (Mestrado em Linguística Aplicada) - Instituto de Letras, Universidade de Brasília, Brasília, 2014.

\section{Páginas eletrônicas}

HELB: HISTÓRIA DO ENSINO DE LÍNGUAS NO BRASIL. Brasília: UnB, 2006. Disponível em: <http://www.helb.org.br/>. Acesso em: 20 maio 2015. Página HELB (Programa de Pós-Graduação em Ling. Aplicada da UnB), coordenada por ALMEIDA 
FILHO, JCP desde 2007. A página traz uma linha do tempo com os principais fatos, datas e personagens da história di ensino de línguas no país, um acervo de documentos importantes como leis e resoluçóes, uma bibliografia sobre a história do ensino de línguas e uma revista especializada no tema da história.

\section{Revista}

REVISTA HELB. Brasília: UnB, 2007. Disponível em: <http://www.helb.org.br/ index.php?option=com_content\&view=article\&id=157\&Itemid=8>.

Acesso em: 20 maio 2015.

Revista HELB contendo (a) uma linha do tempo com principais datas, personagens e feitos no âmbito do Ensino de Línguas no Brasil, (b) uma base bibliográfica básica para estudos de natureza histórica, (c) um acervo de leis e resoluçóes para regular o Ensino de Línguas no Brasil, e (d) uma REVISTA (Revista Helb) especializada em artigos de natureza histórica, única no país desde 2007.

\section{Eventos}

SEMINÁRIO DE HISTÓRIA DO ENSINO DE LÍNGUAS, 1., 2009, Aracaju. Anais... Aracajú: Ed. da UFS, 2009.

I SEHEL (1 ${ }^{\circ}$. Seminário de História do Ensino de Línguas, realizado em Aracaju, Sergipe, entre 3 e 6 de novembro de 2009, organizado por Luiz Eduardo Oliveira, coordenador do Projeto PRO-HELB/CAPES-CNPq).

FORUM DA PROFISSIONALIDADE NO ENSINO DE LÍNGUAS: HISTÓRIA, POLÍTICAS E ÉTICA NA FORMAÇÃO DOCENTE. 1., 2014, Londrina. Anais... Londrina: Ed. da UEL, 2014.

Realizado na Universidade Estadual de Londrina, de 7 a 29 de setembro de 2014 com organização de Simone Reis, do PPGEL/UEL. Lançamento do documento CARTA DE LONDRINA a partir de contribuiçóes dos participantes reunidos em sessão plenária.

COLÓQUIO INTERNACIONAL EDUCAÇÃO E CONTEMPORANEIDADE, 8., 2014, Aracajú. Anais... Aracajú: EDUCON, 2014.

\section{Disciplinas de história na graduação e pós}

Introdução da disciplina História do Ensino de Línguas no Brasil no currículo do Programa de Pós-Graduação em Linguística Aplicada, Universidade de Brasília. Acesso eletrônico ao Programa: <www.pgla.unb.br>. Na graduação não há registro de cursos de Letras que tenham inovado na criação de uma atividade ou disciplina 
específica que tratem da evolução e sentidos do Ensino de Línguas ao longo dos tempos e, especialmente, no século XX, embora seja o século 19 que tenha merecido o livro de natureza histórica mais recente no país.

\section{Grande ausência}

A produção de natureza histórica é relativamente pequena, mas é particularmente omissa no que se refere à história do ensino do Português L1 no Brasil a exemplo do livro fundante de Valnir Chagas (1957) para o ensino de línguas estrangeiras no sistema escolar brasileiro. A exceção esperançosa é a recente dissertação de mestrado de Marília Carvalho Batista defendida no Programa de Pós-Graduação em Linguística Aplicada da UnB e que promete avançar numa nova etapa de pesquisa em nível de doutorado na Europa, em Portugal. Nesse trabalho pioneiro, Batista (2014) inicia a coleta e organização de dados com os quais será possível escrever a história do ensino da língua materna, o Português como L1 no Brasil.

\section{Funções do estudo da história}

O propósito do estudo da História geral para nossos fins neste trabalho seria o de provocar o leitor a refletir sobre modos de viver e de se organizar socialmente ao longo do tempo e em dados lugares em outras épocas, na busca de sentidos do passado que os explique no presente. E uma vez que presente e passado estáo indissociavelmente vinculados na História, o ensino e o estudo dessa disciplina se tornam imprescindíveis para um entendimento mais satisfatório do tempo que vivemos.

A palavra história tem sua origem nas "investigaçóes" de Heródoto, cujo termo

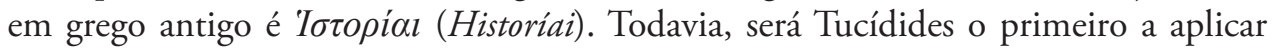
métodos críticos, como o cruzamento de dados e fontes diferentes na composição da narrativa histórica.

Os historiadores usam várias fontes de informação para (re)construir a sucessão de processos históricos como, por exemplo, escritos, gravaçóes, entrevistas (História Oral) e achados arqueológicos. Algumas abordagens são mais frequentes em certos períodos do que em outros. O historiador procura no presente, respostas sobre o passado, ou seja, é influenciado pelo presente na sua interpretação densa.

Historiografia significa "escrita da história". Tanto no sentido de "como a história deve ser escrita" (uma teoria e uma metodologia da história), quanto no sentido de "como a história foi escrita" (uma história da história).

As universidades e associaçóes de professores de línguas vão se beneficiar muito dos estudos de cunho histórico no âmbito da aprendizagem e do ensino de línguas. Ao se abrirem para esse flanco de estudos, vão apoiar de certo modo os estudos identitários que permitem o confronto dos profissionais e aprendizes de professores com aspectos da identidade da área de AELin. O vazio de estudos da HELB afeta principalmente a 
representação da área profissional e teórica (de pesquisa) despolitizando e esvaziando a representação profissional completa e enfraquecendo as chances de (man)termos fortes políticas públicas. Professores de línguas nas universidades são, é claro, duramente afetados quando não se dedicam aos estudos teóricos relevantes da área: acabam representados como mera área de serviço a ser apoiada por teóricos de áreas contíguas ou de contato que passam o ter o domínio sobre seus desígnios, geralmente pouco promissores academicamente e lamentavelmente estagnados ou indutores de prejuízos para o país, suas políticas e seus sistemas de ensino.

\section{Concluindo}

A materialidade de palestras e mesas de debates raras da natureza histórica do ensino de línguas de que participei nos últimos anos depois do ano 2000, como as realizadas em Aracaju (Histórias do Ensino das Línguas), o VIII Colóquio Internacional Educação e Contemporaneidade - o EDUCON- em setembro de 2014, após o I SEHEL de Aracaju na UFS em 2009 e do Seminário História, Políticas e Ética na Profissionalidade (em Londrina) em setembro de 2014, em si mesmos já significam que vamos interpretá-los como parte do movimento rumo a uma consciência e práxis renovadoras em âmbito nacional e quiçá continental.

$\mathrm{O}$ que falta para os papeis esparsos darem lugar à página histórica afirmativa e conscientizadora do livro? Falta em primeiro lugar nos convencermos de que o estudo e a narrativa da nossa história do Ensino de Línguas possuem um lugar honroso na formação que vai muito além do estudo estereotipado de características dos métodos de ensino numa sequência cronológica ao final do Curso de Letras. Na pós-graduação, é auspiciosa a introdução de uma disciplina de história que incentive a pesquisa esclarecedora do porquê ensinamos do modo como ensinamos no país nos vários períodos vividos. A história cruza em muitos projetos com o estudo das políticas de ensino de línguas. A consciência facultada pelas pesquisas, livros, artigos e eventos sobre os sentidos do nosso percurso será, no entanto, o valor auferido mais valorizado.

A prática, ainda que dinâmica, compensadora e monumental como neste país, não leva necessariamente à adequada teoria e nem à consciência de área. A exploração histórica, essa, sim, nos conduz à tomada de consciência sobre o passado com amplas possibilidades de projeçóes de um futuro que desejemos. A área de PLE, por exemplo, é muito antiga e por volta dos anos 80 do século anterior era bastante praticada, mas a consciência de área era praticamente nula nas universidades e escolas de idiomas. A consciência logra abrir novos caminhos passando por associaçóes, abertura de espaços para a pesquisa, para publicaçóes, revistas e eventos.

O olhar histórico nos faz ver que Wigdorsky e Gomes de Matos mostraram indícios de construção da área de Ensino de Línguas e bastante da sua incipiência na América do Sul na histórica série Current Trends in Linguistics (antecipando-se à Linguística Aplicada), publicada em 1966. Leituras sobre ações nos países sulamericanos quanto a 
políticas de ensino de línguas, nos revelam que Chile e Argentina possuem registros de consciência de área por publicaçôes de pioneiros já no início do século 20 . O Brasil tem seus primeiros livros teóricos publicados em 1935, mas na minha formação eles surgem apenas antes da virada do século. Em 80 anos, ganhamos mais consciência, mas pouco dela se converteu em publicaçóes históricas novas e muito pouco se converteu em

políticas de estado e reconhecimento de área. É por mais presença de oportunidades de encontro dos professores na ativa e em formação com a História do Ensino de Línguas do seu país que este artigo advoga e é com essa justificação que o texto foi aceito para aparecer nesta publicação.

\section{THE MISSING PAGE: CONTRIBUTIONS TO A HISTORY OF LANGUAGE TEACHING IN BRAZIL}

- ABSTRACT: Language teaching is a professional practice and a theoretical area. This area is also known as Acquisition and Language Teaching (ALT) or simply Language Teaching, and includes the process of educating agents that contribute to these processes. These processes have always existed in the educational history of the country, but the literature is scarce and there is very little supply of this specialty as a discipline in the curricula of Letras Courses in the area of Language Studies. In this article, I return to writing about the history of characters, costumes and storyline of language teaching in Brazil not to signal periods but to point to the emergence in the area of points of consciousness, as I turn to a discussion of the lack of a historical sense of the field of language teaching (foreign languages in general and Portuguese as a FL in particular) to form a mature and thriving scientific discipline of FL history in undergraduate curricula of Letras courses and in postgraduate programs in Appolied Linguistics in the country.

- KEYWORDS: Language teaching history in Brazil. Language Learning and Teaching. Teaching languages: historical aspects. History of language teaching. Language teacher education.

\section{REFERÊNCIAS}

BATISTA, M. C. Pontos e entrepontos: apontamentos cronológicos para uma narrativa histórica do ensino de língua portuguesa: L1 em ambiente escolar no Brasil. 2014. 255 f. Dissertação (Mestrado em Linguística Aplicada) - Universidade de Brasília, Instituto de Letras, Brasília, 2014.

CHAGAS, V. Didática especial de línguas modernas. São Paulo: Nacional, 1957.

WIGDORSKY, L.; GOMES DE MATOS, F. The teaching of foreign languages in South America. In: LADO, W. R. et al (Ed.). Currents trends in linguistics. The Hague: Mouton, 1968. p.44-71. (Ibero-American and Caribbean Linguistics; v.4). 